\title{
Akuntabilitas Laporan Keuangan Lembaga Amil Zakat di Kota Semarang
}

\author{
NIKMATUNIAYAH, MARLIYATI \\ Politeknik Negeri Semarang, JI Prof Soedharto SH Tembalang Semarang \\ email: nikmatuniayah@rocketmail.com
}

\begin{abstract}
This study aimed to evaluate the system of zakah management and accountability Financial Statements amil zakat institutions. The research method uses descriptive qualitative analysis with multiple models LAZ case study that has the widest distribution of zakat in Semarang. Case studies include: BAZNAS Semarang, LAZIS Baiturrahman, PKPU, DPU Daarut Tauhiid, Rumah Zakat, Dompet Dhuafa, and Baitul Maal Hidayatullah (BMH). The results showed that the Financial Report is available entirely in LAZ, except the Statement of Canges in Asset under Management. The accounting system entirely $100 \%$ available, except flowchart and journals. Internal controls have not been fully complied with and the bulk LAZ yet presentation of financial statements in accordance with SFAS 109. Financial Statements Accountability embodies responsibility to the community, the state, and God (Allah Swt).
\end{abstract}

Keywords: accounting system, zakah of management, accountability, financial statements

\begin{abstract}
Abstrak. Penelitian ini bertujuan untuk mengevaluasi sistem pengelolaan zakat dan akuntabilitas Laporan Keuangan lembaga amil zakat. Metode penelitian menggunakan analisis kualitatif deskriptif dengan model multiple case study LAZ yang memiliki distribusi zakat terluas di Kota Semarang. Studi Kasus meliputi: BAZNAS Kota Semarang, LAZIS Baiturrahman, PKPU, DPU Daarut Tauhiid, Rumah Zakat, Dompet Dhuafa, dan Baitul Maal Hidayatullah (BMH). Hasil penelitian menunjukkan, bahwa Laporan Keuangan tersedia seluruhnya di LAZ, kecuali Laporan Perubahan Aset Kelolaan. Sistem akuntansi seluruhnya $100 \%$ tersedia, kecuali flowchart dan jurnal. Pengendalian intern belum sepenuhnya dipatuhi dan sebagaian besar LAZ belum menyajian Laporan Keuangan sesuai PSAK 109. Akuntabilitas Laporan Keuangan merupakan perwujudan tanggung jawab kepada masyarakat, negara, dan Tuhan (Allah Swt).
\end{abstract}

Kata kunci : sistem akuntansi, pengelolaan zakat, akuntabilitas, laporan keuangan

\section{Pendahuluan}

Sejak dicanangkannya Undang-Undang No. 38 tahun 1999, pengelolaan zakat di Indonesia mengalami perubahan yang berbeda dengan sebelumnya. Jika sebelumnya zakat dikelola oleh kepanitiaan berkala di masjid/mushola, atau disalurkan kepada saudara atau orang terdekat, sekarang telah dikelola secara modern oleh Lembaga Amil Zakat (LAZ). Atsmosfer ini membawa dampak bertambahnya jumlah kelompok masyarakat yang mendirikan lembaga zakat - dengan menggunakan label lembaga yang berbedabeda.
Sampai dengan akhir tahun 2009, telah hadir puluhan ribu organisasi, baik besar maupun kecil, yang terlibat dalam pengelolaan zakat (Juwaini, 2011).

Tabel 1

Lembaga Zakat di Indonesia

\begin{tabular}{|l|l|r|}
\hline No & Organisasi / LAZ & Jumlah \\
\hline 1 & BAZNAS & 1 \\
\hline 2 & BAZDA Propinsi & 33 \\
\hline 3 & BAZDA Kabupaten/ Kota & 434 \\
\hline 4 & BAZ Kecamatan & 4800 \\
\hline 5 & BAZ Kelurahan & 24000 \\
\hline
\end{tabular}

Received: 8 Agustus 2015, Revision: 17 Oktober 2015, Accepted: 26 Desember 2015

Print ISSN: 0215-8175; Online ISSN: 2303-2499. Copyright@2015. Published by Pusat Penerbitan Universitas (P2U) LPPM Unisba Terakreditasi SK Kemendikbud, No.040/P/2014, berlaku 18-02-2014 s.d 18-02-2019 


\begin{tabular}{|l|l|r|}
\hline 6 & LAZ Propinsi & 16 \\
\hline 7 & LAZ Kabupaten/Kota & 31 \\
\hline 8 & UPZ & 8680 \\
\hline & Total & 38013 \\
\hline
\end{tabular}

Sumber: Depag, FOZ (Juwaini, Ahmad 2011)

Potensi zakat di Indonesia yang mencapai 217 trilliun rupiah merupakan jumlah yang sangat besar yang dapat menjadi solusi finansial dalam mengatasi permasalahan kemiskinan dan ketimpangan di Indonesia (Lubis, Anggraini, dan Rulian , 2014). Sugiyo et al. (2009) menyatakan, bahwa potensi ZIS di Jawa Tengah sebesar Rp 4.017.638.091.692. Potensi ZIS khusus Kota Semarang sebesar Rp 153.445.980.564. Namun, besarnya ZIS yang tergali baru Rp 4.082.637.195 untuk Jawa Tengah dan Kota Semarang sebesar Rp 2.013.776.252. Namun nyatanya angkanya masih jauh dari harapan, rata-rata keterserapan ZIS oleh LAZ di Jawa tengah hanya 0,1 persen.

Lestari, et al. (2015) menunjukkan, bahwa "mayoritas Muslim masih membayarkan zakatnya secara individual langsung ke mustahik, disamping pemahaman keagamaan yang bersifat konservatif, faktor kepercayaan masih menjadi kendala pengelolaan zakat." Delapan belas (18) survey Public Interest Research and Advocacy Center (PIRAC) menunjukkan bahwa tingkat kepercayaan masyarakat pada lembaga zakat pada tahun 2004 hanya 15\% (Lestari, et al 2015). Nikmatuniayah (2014) membuktikan, bahwa masih terdapat kelemahan dalam kepatuhan terhadap pengendalian intern LAZ, antara lain ditunjukkan dalam hal melemahnya pemisahan tugas, pemegang otorisasi, rotasi jabatan, dokumen tidak bernomor urut tercetak, dan pengawasan internal.

Fathurrohman, Sobarna, Rasyid. (2014) telah meneliti kinerja nazhir dalam mengelola wakaf di Kota Bandung. Hasil penelitian menyimpulkan, bahwa pengelolaan wakaf di Kota Bandung, masih bertumpu pada kepercayaan personal/individual, bukan kepercayaan pada sistem nazhiroh (kelembagaan). Kondisi ini sekaligus juga menunjukkan kerapuhan dan kelemahan pengelolaan wakaf secara berkelanjutan dan bertanggung jawab, karena lemahnya pengawasan terhadap pra pengelola wakaf (Nazhir) dalam menjalankan aktivitasnya. Masalah kepercayaan dan profesionalitas menjadi prasyarat penting lembaga-lembaga zakat saat ini dan ke depan (Jahar, 2010).
Untuk meningkatkan kepercayaan masyarakat terhadap LAZ dibutuhkan tata kelola organisasi yang baik, yaitu terciptanya transparansi dan akuntabilitas LAZ.

Kusmiati, (2015) mengungkapkan, bahwa "Sebuah institusi dikatakan sehat ketika pengelolaan yang terjadi transparan, akuntabel, birokratif namun tidak kaku, memegang standar baku mutu dan mempunyai kejelasan dalam target dan sasaran mutu yang ingin dicapai." Untuk mewujudkan akuntabilitas LAZ diperlukan sebuah organisasi yang dapat menyuguhkan laporan keuangan zakat secara transparan dan relevan, serta sistem pengelolaan zakat yang baik. LAZ diharapkan dapat menyajikan laporan keuangan zakat sesuai dengan standar yang telah dibuat oleh Ikatan Akuntan Indonesia (IAI) yaitu Pernyataan Standar Akuntansi Keuangan (PSAK) No 109. Penerapan standar PSAK 109 dimulai pasca 2008, yang sebelumya LAZ masih mengacu pada PSAK 45 tentang pelaporan keuangan organsiasi nirlaba. Sehubungan dengan harmonisasi PSAK terhadap IFRS, maka dibuat dan ditetapkan PSAK 109 tentang akuntansi zakat dan infak/sedekah dengan kerangka dasar PSAK 101 (Lembaga Syariah Komersil).

Akuntabilitas pada sektor nonprofit hingga saat ini masih merupakan wacana yang menarik, disebabkan sifat organisasi nonprofit yang sangat berbeda dari organisasi profit (Siskawati, Eka et.al. 2014). Dalam melaksanakan kegiatan operasionalnya organisasi non profit, yakni LAZ menerima donasi dari donatur baik berbentuk benda maupun uang. Untuk menjaga kepercayaan masyarakat yang telah menyumbangkan sebagian hartanya, pengelola LAZ diharapkan dapat menyajikan laporan keuangan zakat sesuai PSAK 109. Sedangkan penyusunan laporan keuangan zakat yang akuntabel dapat dilakukan, karena implementasi Akuntansi Zakat berlaku efektif.

Berdasarkan paparan tersebut maka artikel ini bertujuan untuk menganalisis implementasi Sistem Pengelolaan Zakat dan akuntabilitas laporan keuangan LAZ. Indikator implementasi Sistem Pengelolaan Zakat dilihat dari aspek ketersediaan Laporan Keuangan, Sistem Akuntansi, dan pengendalian internal berdasarkan PSAK 109 IAI.

\section{Sistem Pengelolaan Zakat}

Ditinjau dari segi bahasa, kata zakat memunyai beberapa arti, yaitu al-barakatu 
' keberkahan', al-namaa 'pertumbuhan', ath-thaharatu 'kesucian' dan ash-shalahu 'keberesan' (Majma Lughah al-Arabiyyah, hlm 396). Sedangkan secara istilah zakat berarti bagian dari harta dengan persyaratan tertentu yang diwajibkan Allah kepada pemiliknya untuk diserahkan kepada yang berhak menerimanya dengan persyaratan tertentu pula (Purwanto, April 2008).

Sistem Akuntansi merupakan sekumpulan prosedur yang saling terkait satu sama lain dan membuat sebuah standar yang sama dalam menjalankan tugas organisasi (Krimiaji, 2010: 2). Prosedur tersebut dapat berupa kegiatan-kegiatan klerikal seperti tata cara penulisan, tata cara perhitungan, tata cara penyeleksian, dan prosedur lainnya sesuai dengan kebutuhan organisasi.

Berkaitan dengan prosedur yang merupakan subsistem, diungkapkan adanya kelengkapan dari prosedur berupa flowchart dan alur otorisasi. Prosedur yang diungkapkan dalam penelitian ini biasa disebut juga Standard Operation Procedures (SOP). Flowchart merupakan diagram alur kerja yang memberikan gambaran secara visual bagaimana prosedur dapat dijalankan. Berdasarkan penelitian Rifki, Muhamad (2006) disebutkan bahwa, "Hanya 37,5\% OPZ yang memiliki flowchart walaupun dalam kenyataannya belum semua prosedur yang telah disusun memiliki flowchart yang lengkap.

Sistem pengelolaan zakat dapat terdiri dari prosedur penerimaan zakat, prosedur pengeluaran zakat, dan prosedur pelaporan zakat untuk publik. Prosedur penerimaan zakat meliputi proses yang mengatur bagian penerimaan menerima zakat dan mencatatnya dalam buku sumber penerimaan zakat. Sebaliknya, prosedur pengeluaran zakat menggambarkan alur bagian pengeluaran ketika mengeluarkan dana zakat dan mencatatnya dalam buku pengeluaran zakat. Output dari sistem pengelolaan zakat adalah Laporan keuangan zakat yang disusun berdasarkan PSAK 109 Ikatan Akuntan Indonesia (IAI, 2011). Laporan keuangan yang dimaksud meliputi: Neraca (Laporan posisi keuangan); (b) Laporan Perubahan Dana; (c) Laporan Perubahan Aset Kelolaan; (d) Laporan Arus Kas; dan (e) Catatan atas laporan keuangan.

\section{Sistem Pengendalian Internal}

Komponen model pengendalian internal berdasarkan COSO terdiri dari lingkungan pengendalian, aktivitas pengendalian, perhitungan risiko, informasi dan komunikasi, dan pemantauan (Krismiaji, 2010: 222). Lingkungan pengendalian menggambarkan efek kolektif dari berbagai faktor pada penetapan, peningkatan, atau penurunan efektivitas prosedur dan kebijakan khusus.

Ada empat fungsi pengendalian intern, yaitu: menjaga aktiva (safe guarding of assets), mengecek keakuratan dan reliabilitas data akuntansi (cheking the accuracy and reliability of its accounting data), meningkatkan efesiensi operasional (promoting operational efficiency), dan mendorong ditaatinya kebijakan manajemen (encourage adherence to prescibed managerial polices).

Berdasarkan penelitian Rifki, Muhamad (2006) disebutkan bahwa,

sistem pengendalian internal dilihat dari kriteria sebagai berikut: (1) Struktur organisasi yang memadai, (2) Job Deskripsi, (3) Rotasi kerja dan cuti berkala, (4) Penggunaan dokumen yang bernomor urut tercetak, (5) adanya Divisi khusus Akuntansi yang terpisah dengan Bagian operasional.

Ke lima kriteria tersebut dipakai untuk mengidentifikasi kepatuhan sistem pengendalian internal LAZ. Apabila semua kriteria diataati berarti pelaksanaan pengendalian internal dikatakan baik.

\section{Laporan Keuangan Zakat}

Fungsi kedua sistem informasi akuntansi adalah memberikan informasi yang bermanfaat untuk pembuatan keputusan oleh manajemen. Penyusunan laporan keuangan (financial statement) melibatkan beberapa aktivitas sebagai berikut: (1) Membuat neraca saldo dengan tujuan untuk menguji keseimbangan debit dan kredit akuntansi. (2) Melakukan penyesuaian yaitu mencatat transaksi-transaksi khusus yang hanya dicatat pada akhir periode saja. (3) Menyusun laporan keuangan yang teridiri dari Neraca (Laporan perubahan posisi keuangan), Lapran Perubahan Dana, Laporan Perubahan Aset Kelolaan, Laporan Arus Kas dan Catatan atas Laporan Keuangan.

Menurut PSAK 109 (IAI, 2011) disebutkan bahwa entitas amil menyajikan pos-pos dalam neraca (laporan posisi keuangan) dengan memperhatikan ketentuan dalam PSAK terkait, yang mencakup tetapi tidak terbatas pada Aset, Kewajiban, dan Saldo dana. Amil menyajikan laporan perubahan dana zakat, dana infak/sedekah, dana amil, dan dana nonhalal. Entitas amil menyajikan 


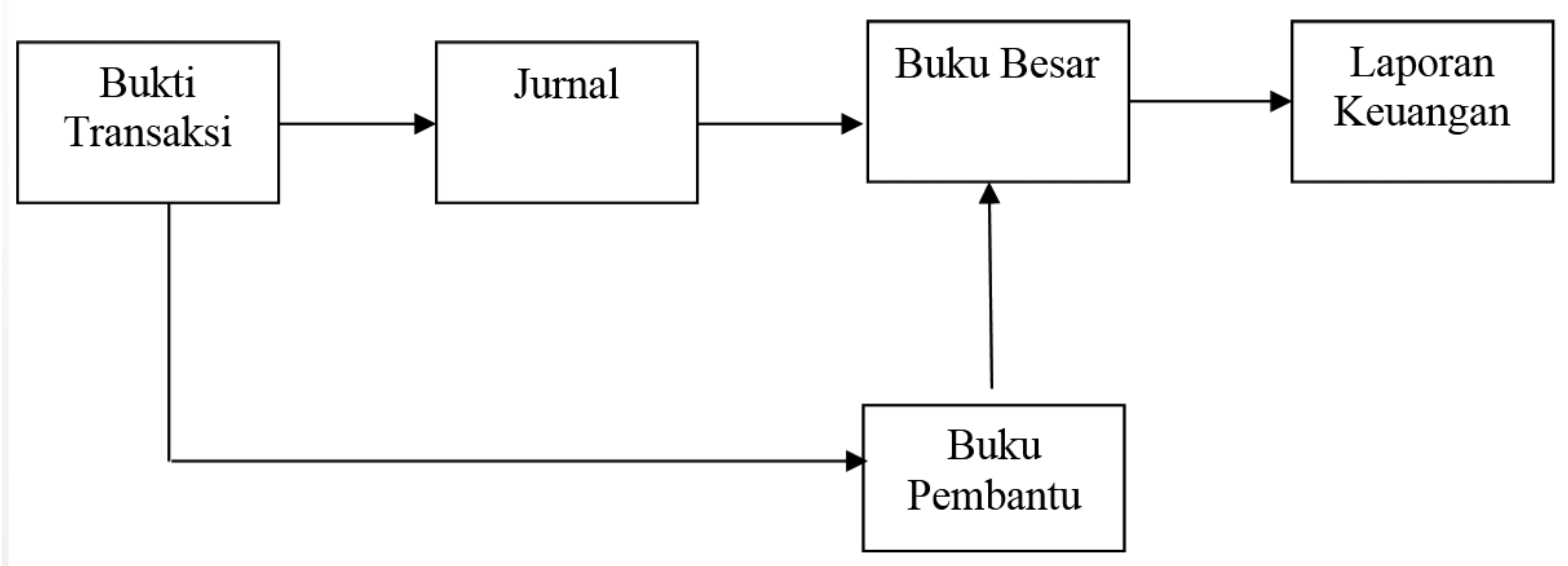

Gambar 1

Proses Penyusunan Laporan Keuangan

laporan perubahan aset kelolaan yang mencakup tetapi tidak terbatas pada: (a) Aset kelolaan yang termasuk aset lancar (b) Aset kelolaan yang termasuk tidak lancar dan akumulasi penyusutan (c) Penambahan dan pengurangan (d) Saldo awal (e) Saldo akhir.

\section{Akuntabilitas Lembaga Amil Zakat}

Akuntabilitas dibutuhkan LAZ sebagai wujud pertanggungjawaban kepada pemangku kepentingan Zakat. Berbagai pihak yang terkait dengan LAZ seperti muzaki, masyarakat, negara menuntut agar LAZ lebih transparan dan akuntabel dalam laporan penggunaan dana tersebut. LAZ harus bersifat akuntabel terhadap berbagai pihak, yaitu penyandang dana, penerima manfaat, dan diri organisasi itu sendiri. Akuntabilitas pada penyandang dana merupakan akuntabilitas yang bersifat ke atas (upward), berupa hubungan antara organisasi dengan pihak donor, pemerintah badan-badan yang sengaja "memberikan dan khusus untuk tujuan khusus" kepada LAZ.

Dalam konteks ini, transparansi menjadi kontrol muzaki atau masyarakat terhadap LAZ sehingga transparansi dikaitkan dengan akses bagi masyarakat untuk mendapatkan informasi penggunaan dana sebanyak mungkin. Masyarakat harus mengetahui sejumlah hal, antara lain: piagam organisasi, dan mekanisme kontrol internal dan eksternal. Christina. P \& Irianto, Gugus (2013) telah menemukan akuntabilitas perpuluhan sebagai milik Tuhan, akuntabilitas perpuluhan sebagai tanda pengakuan, akuntabiliats perpuluhan sebagai tanda kasih dan kemurahan hati, akuntabilitas sebagai tanda iman dan kepercayaan, akuntabilitas perpuluhan sebagai tangung jawab diri terhadap gereja, akuntabiliats perpuluha sebagai tanggung jawab sosial terhadap orang-orang yang membutuhkan.

Huda \& Sawarjuwono, (2013) telah mengidentifikasi persoalan akuntabilitas yang dihadapi organisasi pengelola zakat/ OPZ. Hasil riset menunjukkan tumpang tindihnya program pemberdayaan antar OPZ, data muzaki dan mustahik tidak akurat, terbatasnya kemitraan OPZ, kebijakan pemerintah bertentangan dengan program pendayahgunaan, belum didapatkan model promosi murah dan keterbatasan tenaga amil yang profesional. Akuntabilitas dapat dilakukan dengan menyajikan laporan keuangan zakat yang akuntabel dan transparan.

Manajemen LAZ secara berkala harus menerbitkan laporan keuangan. Laporan ini menjadi strategis dalam rangka meningkatkan akuntabilitas dan transparansi kepada muzaki dan utamanya kepada Tuhan, sehingga akan menimbulkan kepercayaan terhadap muzaki. Seperti yang diungkapkan oleh Wasila, Siti \& Shonhadji, Nanang (2014),

"Akuntabilitas ditetapkan dalam organisasi meliputi aspek fisik, moral dan spiritual. Aspek fisik dari penelitian ini adalah laporan keuangan sementara aspek moral dan sipiritual adalah perwujudan akuntabilitas organisasi kepada Allah dengan mencoba menjalankan kegiatannya berdasarkan syariah."

\section{Metode Analisis}

Populasi penelitian adalah Lembaga Amil Zakat di Kota Semarang Propinsi Jawa Tengah. Penelitian ini menggunakan model multiple case study dengan kriteria LAZ yang memiliki sumber penerimaan zakat 
dan distribusi terluas. Studi kasus terpilih: BAZNAS Kota Semarang, Lazis Baiturrahman, DPU Daarut Tauhid (DPU DT), Rumah Zakat, PKPU, Dompet Dhuafa, Baitul Maal Hidayatullah (BMH). BAZNAS Kota Semarang adalah BAZ yang kelola pemerintah. Lazis Baiturrahman merupakan lembaga zakat berbasis Masjid. BMH adalah LAZ berbasis ormas Islam dan DPU DT berbasis pesantren. Dompet Dhuafa adalah LAZ yang tertua dan berbasis media massa. Lainnya PKPU dan Rumah Zakat merupakan LAZ yang berbasis yayasan profesional.

Artikel ini menggunakan data primer dan sekunder. Data primer diperoleh dengan mengantar kuesioner secara langsung untuk mengetahui kegiatan operasional LAZ. Kuesioner ini digunakan untuk memperoleh data mengenai sejauh mana proses pengelolaan dana LAZ, pertanggungjawabannya kepada masyarakat sesuai dengan prinsip syariah, keadaan manajemen LAZ, dan sistem dan prosedur akuntansi yang diterapkan dalam pengelolaan dana.

Data primer tersebut diperoleh secara mendalam melalui teknik pengamatan dan kuesioner. Tim peneliti mengadakan peninjauan (survei lapangan) ke objek penelitian dengan melakukan wawancara secara langsung kepada pihak-pihak yang terlibat dengan pengelolaan zakat. Melalui teknik pengamatan dapat dilihat prosedur penerimaan dan pengeluaran zakat secara nyata. Sedangkan data-data sekunder diperoleh dalam bentuk laporan keuangan, publikasi-publikasi dan SOP. Selanjutnya, datadata tersebut diklasifikasikan sesuai dengan pokok bahasan penelitian. Pengumpulan data dilaksanakan dalam waktu dua bulan pertama 2015.

Tulisan ini menggunakan model multiple case study yang objeknya adalah beberapa LAZ yang ada di Kota Semarang dengan analisis kualitatif deskriptif. Metode penelitian ini meliputi pengambilan dan formulasi konsep praktis. Data primer dalam penelitian ini berupa data kualitatif, yakni kenyataan sosial organisasi (model manajemen, cara operasi, sistem pengendalian intern, sistem informasi akuntansi, dan lain-lainnya) yang ada pada pengelolaan keuangan lembaga amil zakat.

Pendekatan dalam studi ini menghendaki adanya kedekatan jarak antara objek penelitian (yaitu LAZ yang menjadi objek studi dengan peneliti). Karena secara epistimologis pendekatan ini mengklaim, bahwa kenyataan sosial organisasi pada dasarnya adalah relatif dan hanya bisa mengerti oleh subjek yang secara langsung terlibat dalam aktivitas dan masuk ke dalam kerangka referensi yang sedang berlangsung dimana kenyataan sosial organisasi tadi sedang dipelajari. Aspek yang dievaluasi meliputi: (1) Karakteristik LAZ, (2) Ketersediaan Laporan Keuangan, (3) Aspek sistem akuntansi, (4) Sistem pengendalian internal, (5) Media Akuntabilitas publik. Butirbutir pertanyaan kuesioner tersebut diadopsi dari penelitian Muhammad, Rifqi (2006) dengan harmonisasi PSAK 109 IAI (2011).

Tabel 2

Daftar Anggota FOZ Kota Semarang

\begin{tabular}{|l|l|l|}
\hline No. & Nama Lembaga Amil Zakat & Alamat \\
\hline 1 & LAZIS Jateng & Jl Karang rejo Semarang \\
\hline 2 & Dompet Dhuafa & Jl. Abdulrahman Saleh Blok D No 199, Manyaran, Semarang \\
\hline 3. & Nurul Hayat & Jl Pedurungan Semarang \\
\hline 4 & PPPA Darul Qur,an & Jl. Gergaji Dalam Semarang \\
\hline 5 & Baitul Maal Hidayatullah (BMH) & Jl. Watulawang 2/23 Papandayan Gajah Mungkur \\
\hline 6. & Rijalul Qur'an & Jl. Pedurungan Semarang \\
\hline 7 & PKPU & Jl Setiabudi No. 70 Banyumanik Semarang \\
\hline 8 & LAZISMA & Jl Gajah Semarang \\
\hline 9 & LAZISNU & Jl Dr Cipto Semarang \\
\hline 10. & Panti Yatim Indonesia & Jl Pedurungan Semaang \\
\hline 11 & Rumah Zakat & Jl Dr Sutomo No 53 Semarang \\
\hline 12 & Pena Zakat & Semarang \\
\hline 13 & Yatim Mandiri & Jl Mentri Supeno I no 22 Semarang \\
\hline 14 & DPU Daarut Tauhid & Jl Sriwijaya No. 130 Semarang \\
\hline 15 & Bahagia Berbagi Indonesia (BBI) & Jl Kintelan Baru no 32 Semarang \\
\hline 16 & LAZIS Baiturrahaman & Jl Pandanaran 126 Simpang Lima Semarang \\
\hline
\end{tabular}




\section{Hasil Penelitian dan Pembahasan}

Kota semarang adalah kota propinsi yang cukup besar. Kota Semarang memiliki banyak industri besar, kecil, dan UMKM yang melingkupinya. Kota Semarang tumbuh dengan pesat dengan penduduk yang sebagian besar beragama Islam. Jumlah penduduk Islam yang cukup besar merupakan potensi zakat yang cukup besar. Ada banyak Lembaga Zakat yang berdiri di Kota Semarang, baik yang berbentuk ormas, yayasan, baitul maal wattamwil, maupun yang berdiri di bawah pemerintahan. Enam belas LAZ telah tergabung dalam Forum Organisasi Zakat (FOZ), yang merupakan organisasi aliansi sinergi berbagai LAZ.

Berbagai LAZ yang tergabung tersebut membentuk FOZ sebagai reaksi adanya UU no. 18 2014, yang menyatakan bahwa LAZ harus berdiri di bawah organisasi massa Islam, selain itu LAZ harus bersedia bergabung dengan BAZNAS. Bagi LAZ yang sudah bersinergi dengan FOZ, mereka menjadi lebih kuat dan terorganisasi secara massa. Dari enam belas LAZ tersebut diambil enam LAZ dan BAZNAS Kota yang memiliki sumber penerimaan zakat dan distribusi terluas di Kota Semarang. LAZ/BAZ yang terpilih dan bersedia menjadi model studi kasus adalah: Dompet Dhuafa, Baitul Maal Hidayatullah (BMH), PKPU, Rumah Zakat, DPU Daarut Tauhid, dan LAZIS Baiturrahman (LAZISBA), serta BAZNAS Kota Semarang.

\section{Evaluasi Kepatuhan Sistem Pengelolaan Zakat}

Berdasarkan analisis deskriptif profil LAZ diperoleh hasil, bahwa bentuk badan hukum semua LAZ adalah Yayasan, kecuali Baznas Kota semarang yang merupakan lembaga pemerintahan otonom. Seluruh LAZ dan BAZ tersebut posisi karyawan adalah full time, kecuali Rumah Zakat yang memiliki tenaga tidak tetap atau karyawan yang bekerja part time. Karyawan yang tidak tetap disebut agen yang tugasnya mengumpulkan zakat dari para donatur secara mandiri. Besarnya fee yang diterima berdasarkan jumlah target pengumpulan kali empat persen.

Laporan keuangan yang baik adalah yang sesuai dengan standar PSAK 109 IAI. Laporan keuangan tersebut mestinya terdiri dari: Neraca, Laporan Perubahan Aset Kelolaan, Laporan Arus Kas, Laporan perubahan Dana, dan dilengkapi Catatan atas laporan keuangan. Berdasarkan pengamatan diperoleh hasil bahwa laporan keuangan: Neraca, Laporan Arus Kas, dan Laporan perubahan dana sudah tersedia $100 \%$ di LAZ. Sedangkan untuk Laporan Perubahan Aset Kelolaan dan Catatan atas Laporan Keuangan tersedia di LAZ 70\%, perkecualian tersebut untuk PKPU dan LAZISBA.

Sistem informasi Akuntansi yang baik harus meliputi berbagai hal sebagai berikut: ketersediaan prosedur atau SOP, adanya Flowchart sistem, Dokumen yang

Tabel 3

Karakteristik Lembaga Zakat

\begin{tabular}{|c|c|c|c|c|c|c|c|c|}
\hline No & Uraian & Pkpu & DPU DT & Lazisba & $\begin{array}{c}\text { Ru } \\
\text { Mah Zakat }\end{array}$ & $\begin{array}{l}\text { Dompet } \\
\text { Dhuafa }\end{array}$ & $\begin{array}{c}\text { Baznas } \\
\text { Kota }\end{array}$ & ВMH \\
\hline 1 & $\begin{array}{l}\text { Badan } \\
\text { Hukum }\end{array}$ & Yayasan & Yayasan & Yayasan & Yayasan & Yayasan & $\begin{array}{l}\text { Lembaga } \\
\text { Pemerintah }\end{array}$ & Yayasan \\
\hline 2 & $\begin{array}{l}\text { Posisi } \\
\text { Petugas }\end{array}$ & Full Time & Full Time & Full Time & $\begin{array}{l}\text { Full Time \& } \\
\text { part time }\end{array}$ & Full Time & Full Time & Full Time \\
\hline 3 & $\begin{array}{l}\text { Susunan } \\
\text { Pengurus }\end{array}$ & $\begin{array}{l}\text { Dewan } \\
\text { Pengawas } \\
\text { Syariah, } \\
\text { Ketua } \\
\text { Pengurus, } \\
\text { Dewan } \\
\text { Pengawas } \\
\text { manajemen, } \\
\text { Penguru }\end{array}$ & \begin{tabular}{|l|} 
Divisi \\
Pengerahan \\
dana, \\
pembiayaan, \\
admin \& \\
Akuntansi
\end{tabular} & \begin{tabular}{|l|} 
Dewan \\
Pengawas \\
Syariah, \\
Ketua \\
Pengurus, \\
Dewan \\
Pengawas \\
manajemen, \\
Pengurus
\end{tabular} & $\begin{array}{l}\text { Dewan } \\
\text { Pertimbangan } \\
\text { Dewan } \\
\text { Pengawas, } \\
\text { Badan } \\
\text { Pelaksana }\end{array}$ & Lainnya & $\begin{array}{l}\text { Lembaga } \\
\text { Pemerintah } \\
\text { Non } \\
\text { Struktural }\end{array}$ & $\begin{array}{l}\text { Dewan } \\
\text { Pengawas } \\
\text { Syariah, } \\
\text { Ketua } \\
\text { Pengurus, } \\
\text { Dewan } \\
\text { Pengawas } \\
\text { manajemen, } \\
\text { Pengurus }\end{array}$ \\
\hline
\end{tabular}


Tabel 4

Keberadaan Laporan Keuangan

\begin{tabular}{|l|l|c|c|}
\hline No & \multicolumn{1}{|c|}{ Uraian } & Jumlah (LAZ) & Persentase \\
\hline 1 & Neraca & 7 & $100 \%$ \\
\hline 2 & Laporan Perubahan Aset Kelolaan & 5 & $70 \%$ \\
\hline 3 & Laporan Arus Kas & 7 & $100 \%$ \\
\hline 4 & Laporan Perubahan Dana & 7 & $100 \%$ \\
\hline 5 & Catatan atas Laporan Keuangan & 5 & $70 \%$ \\
\hline
\end{tabular}

Tabel 5

Keberadaan Sistem Akuntansi

\begin{tabular}{|l|l|c|c|}
\hline No & \multicolumn{1}{|c|}{ Uraian } & Jumlah (LAZ) & Persentase \\
\hline 1 & Prosedur (SOP) & 7 & $100 \%$ \\
\hline 2 & Flowchart & 6 & $85 \%$ \\
\hline 3 & Kelengkapan Dokumen & 7 & $100 \%$ \\
\hline 4 & Jurnal & 6 & $85 \%$ \\
\hline 5 & Buku Besar & 7 & $100 \%$ \\
\hline 6 & Laporan Keuangan & 7 & $100 \%$ \\
\hline
\end{tabular}

Tabel 6

Kepatuhan Sistem Pengendalian Intern

\begin{tabular}{|l|l|c|c|}
\hline No & \multicolumn{1}{|c|}{ Uraian } & Jumlah (LAZ) & Persentase \\
\hline 1 & Struktur Organisasi & 7 & $100 \%$ \\
\hline 2 & Job Deskripsi & 7 & $100 \%$ \\
\hline 3 & Rotasi kerja dan cuti berkala & 6 & $85 \%$ \\
\hline 4 & Dokumen dengan nomor tercetak & 7 & $100 \%$ \\
\hline 5 & Divisi khusus akuntansi yang terpisah & 5 & $70 \%$ \\
\hline 6 & Auditor internal & 5 & $70 \%$ \\
\hline 7 & Laporan Keuangan diaudit akuntan publik & 5 & $70 \%$ \\
\hline
\end{tabular}

Sumber: Data primer yang diolah

lengkap, penggunaan jurnal, buku besar, dan penyajian laporan keuangan. Dalam aspek: prosedur, kelengkapan dokumen, buku besar, dan laporan keuangan 100\% tersedia di LAZ. Hal tersebut disebabkan perkecualian untuk flowchart yang belum tersedia di $B M H$ dan jurnal belum tersedia di LAZISBA. LAZISBA mengerjakan laporan keuangan menggunakan excell, dimaksudkan agar lebih memudahkan dengan tanpa dibuat jurnal, melainkan langsung direkap dalam database. Sedang tidak tersedianya flowchart di BMH dikarenakan, dia menganggap prosedur yang dimaksud sudah berjalan sehari-hari sebagaimana mestinya. Artinya prosedur mengikuti kelaziman: muzaki datang mengambil formulir, mengisi formulir, lalu menyerahkan donasi, lalu petugas mencatat dan selesai.

Selanjutnya, dalam kepatuhan sistem pengendalian internal sebagai berikut: kepatuhan struktur organisasi, job diskripsi, dokumen bernomor urut tercetak $100 \%$ tersedia di LAZ. Berikutnya aspek rotasi kerja $85 \%$, aspek divisi khusus akuntansi yang terpisah $70 \%$, auditor internal $70 \%$, dan laporan keuangan diaudit juga $70 \%$. Aspek rotasi jabatan tidak dipatuhi oleh BAZNAS, dikarenakan pengelola BAZNAS sendiri adalah pegawai tetap pemerintah negeri. Sedangkan aspek divisi khusus akuntansi yang terpisah tidak dipatuhi oleh Dompet Dhuafa dan Baznas Kota. Baik keduanya menyatakan alasan karena terbatasnya tenaga akuntansi yang terdaftar di LAZ. Berikutnya tidak semua LAZ memiliki auditor internal. Keterbatasan sumber daya manusia dibidang akuntansi terutama yang ahli di bidang audit menjadi alasan BAZNAS kota dan BMH belum memiliki. Sedangkan LAZISBA dan BMH belum memiliki laporan keuangan diaudit akuntan publik.

Berdasarkan Tabel 7 diketahui bahwa 
Tabel 7

Aspek Akuntabilitas Publik

\begin{tabular}{|l|l|c|c|}
\hline No & \multicolumn{1}{|c|}{ Uraian } & Jumlah (LAZ) & Persentase \\
\hline 1 & Papan Pengumuman & 6 & $85 \%$ \\
\hline 2 & Surat/Laporan langsung ke Muzaki & 7 & $100 \%$ \\
\hline 3 & Buletin rutin & 6 & $85 \%$ \\
\hline 4 & Surat Kabar & 6 & $85 \%$ \\
\hline 5 & Majalah & 6 & $85 \%$ \\
\hline 6 & E-mail/internet & 7 & $100 \%$ \\
\hline 7 & Brosur & 7 & $100 \%$ \\
\hline
\end{tabular}

Sumber: Data primer yang diolah

Tabel 8

Analisis Masalah LAZ

\begin{tabular}{|l|l|c|c|}
\hline No & \multicolumn{1}{|c|}{ Uraian } & Jumlah (LAZ) & Persentase \\
\hline 1 & Belum ada standar akuntansi & 2 & $30 \%$ \\
\hline 2 & Kurangnya SDM berpengalaman & 4 & $57 \%$ \\
\hline 3 & Tingginya biaya profesionalisme & 4 & $57 \%$ \\
\hline 4 & Rendahnya kesadaran masyarakat & 5 & $70 \%$ \\
\hline
\end{tabular}

semua LAZ telah memublikasikan laporan keuangan untuk publik. Dalam berbagai aspek yaitu papan pengumuman, surat/laporan ke muzaki, bulletin, surat kabar, majalah, brosur, dan email/internet. Kecuali untuk papan pengumuman tidak tersedia di $\mathrm{BMH}$, bulletin dan majalah belum dibuat oleh BAZNAS. Hal ini dimungkinkan karena BAZNAS mengganggap belum perlu, mengingat lembaganya adalah lembaga independen di bawah pemerintahan kota. Zakat yang ditarik bersifat wajib dan dipotong gaji melalui bendahara masingmasing lembaga pemerintah. Selanjutnya untuk surat kabar hanya LAZISBA yang belum menggunakan, hal ini disebabkan LAZISBA adalah LAZ lokal yang area lahan zakatnya bersifat lokal pula, yakni Kota Semarang dan sekitarnya.

Dari permasalahan yang ditanyakan LAZ yang mengikuti standar akuntansi PSAK 109 dalam penyajian laporan keuangan baru $70 \%$. BAZNAS kota dan semua BAZ daerah yang melikupinya belum mengikuti standar PSAK 109. Hal ini dikarenakan kurangnya sumber daya manusia yang memiliki keahlian akuntansi, terutama Zakat Infak dan Shodaqoh (ZIS). Tingginya biaya profesionalisme dirasakan oleh 57\% LAZ di Kota Semarang. Seperti yang dikemukakan oleh Imam Baihaqi (Pimpinan Dompet Dhuafa Cab. Jateng, 2015), alasan tersebut karena semakin banyak lulusan SI yang memiliki keinginan menjadi pengurus LAZ. Mereka meminta gaji/ fee sesuai standar sarjana, sehingga biaya profesionalisme menjadi tinggi. Dibandingkan dengan luasnya penerimaan zakat yang tidak seberapa, biaya profesional menjadi biaya tinggi bagi LAZ. Padahal sesuai tupoksi tugas pengelola LAZ, sumber daya manusia berlatar belakang D3 cukup memadai (Imam Baihaqi, wawancara 12 Mei 2015).

Yang menyedihkan, 70\% LAZ menyatakan bahwa kesadaran masyarakat untuk membayar zakat masih rendah. Pada umumnya masyarakat lebih suka membayar sendiri zakatnya pada orang miskin yang dekat dengan saudara atau dikenalnya. Sesuai dengan ujaran pimpinan Dompet Dhuafa, Imam Baihaqi yang menyebutkan:

"Orang membayar zakat tahunya baru seba-
tas membayar zakat fitrah yang dibayar se-
tahun sekali. Padahal ada banyak zakat yang
harus dibayar selain zakat fitrah, ada zakat
maal atau zakat profesi. Selain itu masyarakat
lebih senang membayar sendiri zakatnya un-
tuk orang yang dikenal atau saudaranya"

Permasalahan lain yang ditemukan pada waktu wawancara dengan tokoh Amil, ditemukan adanya pengalihan sumber daya manusia yang ahli dari satu LAZ ke LAZ yang lain. Hanya saja eks-karyawan tersebut juga membawa database donatur yang diperoleh dari LAZ sebelumnya. Jadinya seolah-olah ada kesan pembajakan SDM atau perebutan lahan donatur. Masalahnya, kasus ini belum diatur dalam kode etik LAZ, karena pada dasarnya LAZ belum memiliki kode etik profesi 
Amil Zakat. Kaitannya dengan hal tersebut para pimpinan LAZ yang tergabung dalam FOZ dengan diketuai oleh Suroto (Rumah Zakat) merencanakan untuk mengatur hal tersebut dalam kode etik profesi Amil Zakat. Sementara dalam rapat FOZ yang diadakan pada tanggal 11 Mei 2015, telah disepakati aturan main sebagai berikut: Amil diperkenankan berpindah karena suatu alasan yang dianggap baik oleh LAZ sebelumnya. Amil zakat yang berpindah ke LAZ tidak diperkenankan membawa data muzaki ke LAZ yang baru. Amil/ LAZ tidak diperkenankan memasuki lembaga donatur yang sudah menjadi sumber penerimaan LAZ tertentu.

\section{Akuntabilitas LAZ}

Meski muzaki berdalih 'membayar zakat' karena Lillahita'alla (ikhlas) pengelola zakat tidak boleh mengabaikan akuntabilitas Laporan penggunaan dana tersebut. Pengelola zakat tetap menanggung integritas moral kepada masyarakat itu sendiri. Dalam teori keagenan akuntabilitas sebetulnya timbul sebagai konsekuensi logis atas adanya hubungan antara pengelola zakat (agent) dan muzaki dkk (principal), sehingga muncul hubungan yang dinamis berupa agentprincipal relationship. Principal dalam hal ini memberikan kewenangan penuh pada agent untuk melakukan aktivitas operasi organisasi, dengan upaya memanfaatkan sumber dananya untuk kepentingan umat. Konsekuensi atas wewenang tersebut, maka agen harus mempertanggungjawabkan aktivitasnya kepada principal.

Konsteks Agent-principal relationship dalam kajian LAZ lebih luas dibandingkan dengan pengertian di atas. Dalam pengertian umum biasanya prinsipal menunjuk pada pemegang saham (stockholders). Namun prinsipal dalam konteks LAZ dapat berarti luas. Prinsipal yang dimaksud tidak hanya muzaki saja, melainkan pihak-pihak pemangku kepentingan yang berkaitan dengan zakat. Pemangku kepentingan yang dimaksud dapat berupa paguyuban, masyarakat, atau negara.

Menurut Saifa, staf keuangan LAZISBA, secara internal Tim Pelaksana atau pengurus pertama-tama mempertanggungjawabkan kegiatannnya kepada Auditor Internal. Secara khusus LAZISBA kemudian mempertanggungjawabkan kepada Bendahara LAZ, yang selanjutnya bertanggung jawab kepada Dewan Pengawas Syariah. Dewan Pengawas Syariah inilah yang mewarnai kegiatan amil di LAZ. Dewan tersebut juga yang bertanggung jawab mengarahkan dan mempertahankan syariah di pengelolaan LAZ.

Sedangkan dilihat dari aspek pertanggungjawaban amil kepada masyarakat, menurut Shodikin, pimpinan DPU Daarut Tauhid Cabang Semarang, bahwa:

"Tingkat pertama adalah Amil bertanggung jawab kepada masyarakat. Pertanggungjawaban ini ditunjukkan oleh ISO dan laporan keuangan yang diaudit oleh auditor independen. Berikutnya Amil bertanggung jawab kepada Negara, yang dikukuhkan dengan UU LAZ. Selanjutnya berturut-turut bertanggung jawab kepada Nabi Muhammad Saw, dalam hal ini mengacu Hadist Nabi. Dan tanggung jawab puncak ada pada Allah Swt, dengan mendasarkan kegiatan LAZ sesuai AL Qur'an."

Jika dibandingkan berbagai pendapat di atas tampak ada keseragaman pola pertanggung jawaban pengelola zakat sebagai agent kepada para prinsipal-pemangku kepentingan ZIS. Pertama muzaki yang dalam hal ini diwujudkan sebagai masyarakat, adalah 'pemilik' LAZ. Masyarakat memiliki hak mendapat informasi yang terbuka mengenai laporan penggunaan donasi. Prinsipal kedua dalam hal ini adalah pemerintah yang diwujudkan sebagai Negara. LAZ /BAZ berada dalam lindungan hukum Negara, sudah sepantasnya Negara menuntut transparansi Laporan penggunaan Donasi LAZ. Puncak pertanggungjawaban yang tertinggi adalah pertanggungjawaban kepada Tuhan yang dimaksud dalam hal ini adalah Allah Swt.

Pertanggungjawaban kepada Allah Swt memang tidak ada sanksi dunia, melainkan sanksi akherat yang kepastian waktunya tak terbatas. Namun ditilik dari spirit pengelola LAZ, mereka memiliki keyakinan dan penjagaan hati yang kuat untuk tetap istiqomah mengemban amanah mengelola LAZ.

\section{Simpulan dan Saran}

Berdasarkan paparan pembahasan sebelumnya dapat diambil simpulan, bahwa laporan keuangan: Neraca, Laporan Arus Kas, dan Laporan Perubahan Dana sudah tersedia $100 \%$ di LAZ. Sedangkan untuk Laporan Perubahan Aset Kelolaan baru $70 \%$ tersedia di LAZ. Dalam aspek Sistem Akuntansi: prosedur, kelengkapan dokumen, buku besar, dan laporan keuangan $100 \%$ tersedia di LAZ. Kecuali untuk flowchart belum tersedia di BMH dan jurnal belum tersedia di LAZISBA.

Dalam aspek pengendalian intern diperoleh hasil sebagai berikut: ketersediaan struktur organisasi, job diskripsi, dokumen 
bernomor urut tercetak $100 \%$ tersedia di LAZ. Berikutnya, aspek rotasi kerja $85 \%$, aspek divisi khusus akuntansi yang terpisah $70 \%$, auditor internal $70 \%$, dan laporan keuangan diaudit juga $70 \%$. Semua LAZ telah mempublikasikan laporan keuangan untuk publik, dalam berbagai bentuk media yaitu: papan pengumuman, surat/laporan ke muzaki, bulletin, surat kabar, majalah, brosur, dan email/internet. Namun, baru 70\% LAZ yang mengikuti standar akuntansi PSAK 109. Permasalahan yang dihadapi LAZ adalah tingginya biaya profesionalisme (57\% LAZ) dan rendahnya kesadaran masyarakat untuk membayar zakat (70\% LAZ). Akuntabilitas Laporan Keuangan LAZ ditujukan kepada Masyarakat, Negara, dan Tuhan (Allah Swt).

Sebagai solusi atas permasalahan yang dirasakan LAZ disarankan BAZNAZ/FOZ perlu membuat standar operasional (SOP) Sistem Pengelolaan Zakat yang sesuai dengan PSAK 109 IAI. Berikutnya BAZNAS dan LAZ yang tergabung dalam FOZ perlu merumuskan Kode Etik Profesi Amil yang dapat melindungi legalitas LAZ di Indonesia. Penelitian berikutnya dapat diperluas dengan LAZ-LAZ Daerah yang merupakan anggota FOZ, untuk memastikan implementasi Laporan Keuangan LAZ berdasarkan PSAK 109 IAI sampai ke sudut-sudut daerah.

\section{Daftar Pustaka}

Cristina. P, Agustina \& Irianto, Gugus. (2013). Akuntabilitas Perpuluhan Gereja. Jurnal Akuntansi Multiparadigma (JAMAL), Vol. 4, No. 2, Agustus, pp. 165-329.

Krismiaji, (2010). Sistem Informasi Akuntansi. Penerbit YKPN, Yogyakarta.

Kusmiati, Mia. (2015). Membangun Kesehatan Organisasi Institusi Pendidikan Dokter: sebuah Transformasi menuju Akuntabilitas Sosial, MIMBAR, Vol. 31, No. 1, Juni, pp. 123-134.

Fathurrohman T, Sobarna A, Rasyid A.M. (2014). Analisis Deskriptif tentang Kinerja Nadzir Wakaf. MIMBAR, Vol. 30, No 2, Desember, pp.233-242.

Huda, Nurul \& Sawarjuwono, Tjiptohadi. (2013). Akuntabilitas Pengelolaan Zakat melalui Pendekatan Modifikasi Action Research. Jurnal Akuntansi Multiparadigma (JAMAL),
Vol. 4, No. 3, Desember, pp. 330-507.

Ikatan Akuntansi Indonesia. (2011). Pernyataan Standar Akuntansi Keuangan No 109: Akuntansi Zakat Infak/Sedekah. https:// staff.blog.ui.ac.id/martani/files/2011/04/ ED-PSAK-109.pdf. Diakses tanggal 16 Februari 2015.

Jahar, Asep S. (2010). Masa Depan Filantropi Islam Indonesia Kajian Lembaga-lembaga Zakat dan Wakaf, Annual Conference on Islamic Studies Banjarmasin, 1-4 November 2010 (ACIS) ke -10 .

Juwaini, Ahmad. (2011). Strategi Pengembangan SDM Zakat di Indonesia, in: Aflah, Noor: Strategi Pengembangan Zakat di Indonesia, FOZ, pp. 33-41.

Lestari P, Pratiwi U, Ulfah P. (2015). Identifikasi Faktor Organisasional dalam Pengembangan "E-Governanace" pada Organisasi Pengelola Zakat. MIMBAR, Vol. 31, No 1, Juni, pp. 221-228

Lubis D, Anggraini L, dan Rulian N.A (2014), Faktor-faktor yang Mempengaruhi Muzaki dalam Memilih Organisasi Pengelola Zakat, IQTISHODA Jurnal Ekonomi Islam Republika, Republika Kamis, 24 April 2014.

Muhammad, Rifqi (2006). Akuntabilitas Keuangan pada Organisasi Pengelola Zakat (OPZ) di Daerah Istimewa Yogyakarta, Jurnal Akuntansi Dan Investasi, Vol. 7 No. 1. Hal

Nikmatuniayah, (2014). Komparasi Sistem Pengendalian Internal Pengelolaan Lembaga Amil Zakat, Jurnal Akuntansi Multiparadigma (JAMAL), Vol. 5, NO. 3, Desember, pp. 498-510

Purwanto, April, (2008). Cara Cepat Menghitung Zakat. Penerbit Sketsa, Yogyakarta.

Siskawati E, Ferdawati, Surya F. (2015). Model Akuntabilitas Organisasi Non Profit pada Masjid, Jurnal Riset dan Aplikasi: Akuntansi dan Manajemen (JRAAM), Vol 1, No. 1, Maret, pp. 29-41

Sugiyo, Setyawan H.A, Pujiono A. (2009). Model Pemberdayaan Masyarakat Miskin Binaan Lembaga Amil Zakat Jawa Tengah dalam Mengentaskan Kemiskinan yang Bersumber dari Dana Zakat Infak dan Sedekah. Penerbit Universitas Diponegoro, Semarang.

Wasila, Siti \& Shonhadji, Nanang. (2014). A Study on the Zakat and Infaq or Sodaqoh Accounting Application under SFAS 109 in Al-Falah Soscial Fund Foundation (YSDF) Surabaya. The Indonesian Accounting Review, Vol 4, No. 2, Juli, pp. 169-174 